\title{
The interaction between an ice sheet and its atmospheric boundary layer
}

\author{
ALISON HALL" AND KEITH WESTON \\ Department of Geology and Geophysics, and Department of Meteorology, University of Edinburgh, Edinburgh EH9 37Z, Scotland
}

\begin{abstract}
The importance of the atmospheric boundary layer for the coupling between the climate and an ice sheet is investigated using a slab model of the atmospheric boundary layer. The model is shown to give reasonable agreement with observations over Antarctica and it is used to look at the effect of different ice-sheet shapes on the boundary layer. The importance of entrainment in bringing heat to the surface is highlighted and is shown to be particularly significant when the ice profile becomes steeper. The model could be used as part of an energy-balance model of snow in order to incorporate the interplay of the boundary layer and ice-sheet shape in the ablation process. The slab model could also be used in a GCM as a parameterization of these sub-grid scale processes which are at present ignored in models on a global scale.
\end{abstract}

\section{INTRODUCTION}

Experiments with ice-sheet models show that their evolution is particularly sensitive to the parameterization of mass balance, particularly in the ablation zone (Oerlemans, 1981; Hyde and Peltier, 1985). Accumulation depends primarily on synoptic scale motions, while ablation depends on the detailed properties of the boundary layer over the ice sheet. Meteorological studies of the mass balance associated with ice sheets have often focused on GCM simulations of climate (e.g. Manabe and Brocolli, 1985; Kutzbach and Guetter, 1986; Mitchell and others, 1988). The resolution of these models places limitations on their ablility to reproduce boundary-layer characteristics, and their large demands on computer time mean they can only provide snapshots of a steadystate climate for a specific ice-sheet configuration. This is not necessarily the most appropriate approach to take in order to increase understanding of the interaction between mass balance or climate and ice-sheet evolution. On the other hand, models which allow the ice sheet to grow often incorporate highly parameterized climates, which are unable to respond to the evolving ice sheet. In order more fully to understand the way in which mass balance and ablation may change as the ice sheet evolves, a more comprehensive understanding of the boundary- layer processes over ice sheets is required. This paper uses a slab model in order to look at the way in which the atmospheric boundary layer may respond to a change in ice-sheet size and/or shape.

During the last decade or so, measurements over

* Present address: Climatic Research Unit, University of East Anglia, Norwich, Norfolk NR4 7TJ, England.
Antarctica (e.g. Gosink, 1982; Kodama and others, 1989) have given greater insight into the katabatic wind regime of the glacial slopes. These observations can be used, in conjunction with numerical models, to increase our understanding of the boundary-layer processes. In the future, this knowledge will be able to provide a basis for improvements to the parameterization of ablation in icesheet models. In the absence of any reliable data from elsewhere, the model presented here was developed using the observations from Antarctica in the parameterizations and boundary conditions.

\section{THE MODEL}

The concepts of the model are shown in Figure 1. The boundary layer is treated as a layer of cold air flowing over a dome-shaped ice sheet, with a surface profile of slope angle $\alpha$ within a stably stratified environment. The boundary layer is subject to sustained cooling, surface stress, entrainment of the air above and pressure gradient and Coriolis forces. Only mean-layer quantities are evaluated, deviations from well-mixed flow being incorporated into a set of profile parameters, as used by Manins and Sawford (1979). The $s$-axis follows the surface of the ice in the direction of maximum slope, parallel to the direction of flow component $u$. The $y$-axis is directed perpendicularly to the left, in the direction of flow component $v$, parallel to the contours, and the $n$-axis is orientated normal to the $s-y$ plane. The air is treated as a Boussinesq fluid, so that variations in density are ignored, except for those producing a buoyancy force when combined with gravity (Manins and Sawford, 1979); this approximation is reasonable for heights of a few hundred metres. The upper boundary of the model is constrained by a prescribed potential temperature 


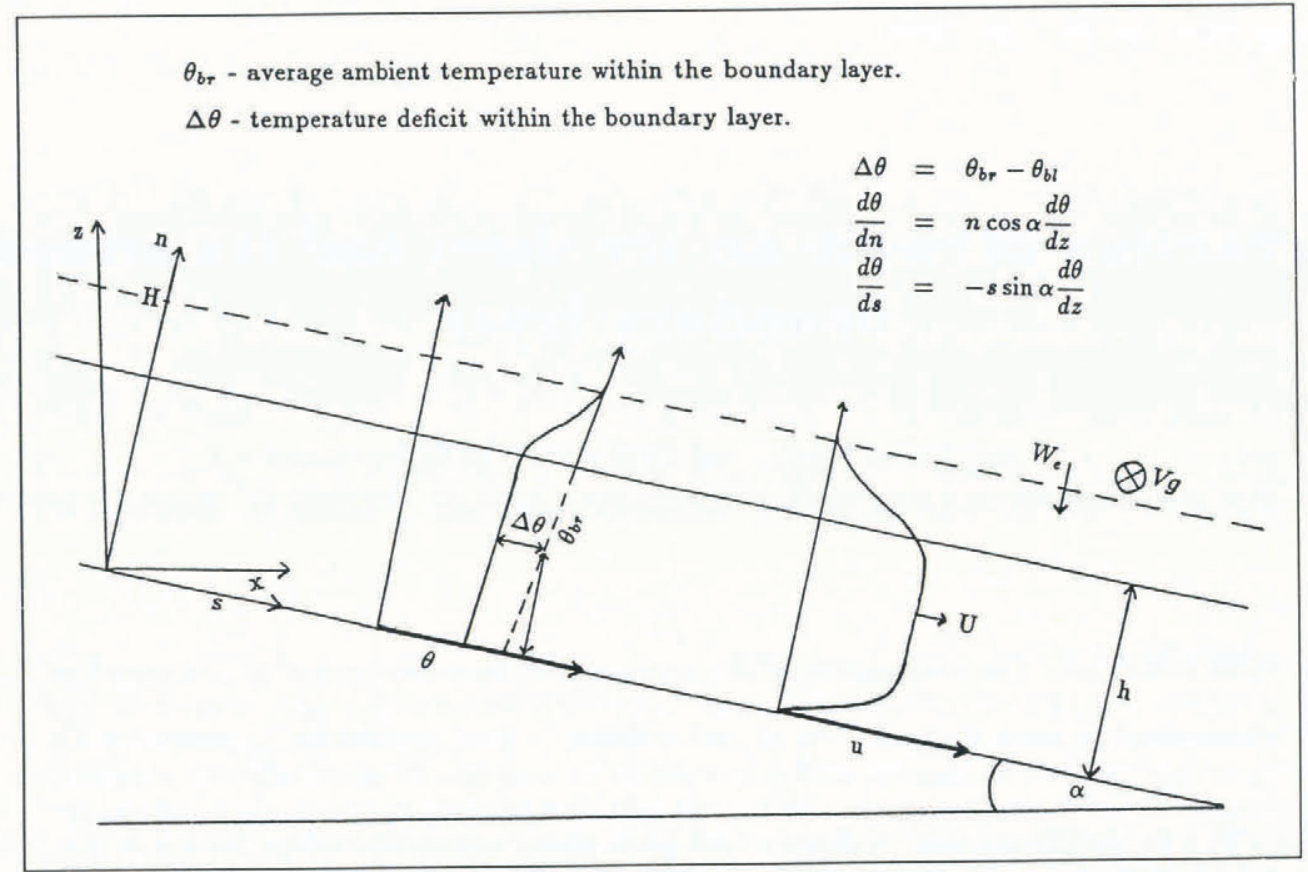

Fig. 1. The idealized boundary layer of the slab model.

gradient $(\mathrm{d} \theta / \mathrm{d} z)$ and wind speed $\left(V_{\mathrm{g}}\right)$. The temperature gradient implies a Brunt-Vaisalla buoyancy frequency $\left(N^{2}\right)$, which is the velocity of propagation of smallamplitude gravity waves. In a stable layer, this is defined as

$$
N^{2}=\frac{g \mathrm{~d} \theta}{\theta_{\mathrm{br}} \mathrm{d} z}
$$

where $g$ is the acceleration due to gravity and $\theta_{\mathrm{br}}$ is the potential temperature of the "ambient" air and is defined in Figure 1. The wind above the boundary layer $\left(V_{\mathrm{g}}\right)$ is assumed to be geostrophic and exclusively in the $y$ direction. Surface cooling is prescribed according to a constant net-radiative divergence in the boundary layer $\left(\partial R_{n} / \partial n\right)$. The air within the boundary layer is acted on by a buoyancy force due to the potential temperature deficit $(\Delta \theta)$, in the ambient temperature field $\left(\theta_{\mathrm{br}}\right)$, and flows down-slope under the influence of this force, combined with the over-riding pressure-gradient force and the Coriolis force. Friction acts at the surface with the ice sheet (surface stresses in the $x$ - and $y$-directions are $\tau_{x}$ and $\tau_{y}$, respectively) and entrainment is permitted with the warmer air above the boundary layer, producing additional drag.

\subsection{The governing equations}

The model is based on the following set of equations for the steady-state conservation of momentum, mass and heat, using the nomenclature given in the previous section and taking $\left(p-p_{\mathrm{a}}\right)$ as the pressure depth of the boundary layer and $\partial p / \partial s$ as the pressure gradient of the ambient air.

$$
\begin{aligned}
& \text { Momentum } \\
& \qquad \begin{array}{l}
w \frac{\partial u}{\partial n}+u \frac{\partial u}{\partial s}=g \frac{\Delta \theta}{\theta_{\mathrm{br}}} \sin \alpha-\frac{1}{\rho} \frac{\partial \rho}{\partial s}-f v+\frac{\partial\left(\tau_{x} / \rho\right)}{\partial n} \\
w \frac{\partial v}{\partial n}+u \frac{\partial v}{\partial s}=\frac{\partial V_{\mathrm{g}}}{\partial n} \frac{\partial(u h y)}{\partial s}+f u+\frac{\partial\left(\tau_{y} / \rho\right)}{\partial n}
\end{array}
\end{aligned}
$$

Hydrostatic balance

$$
\frac{\mathrm{d} w}{\mathrm{~d} t}=\frac{1}{\rho} \frac{\partial}{\partial n}\left(p-p_{\mathrm{a}}\right)-g \frac{\Delta \theta}{\theta_{\mathrm{br}}} \cos \alpha .
$$

Heat

$$
w \frac{\partial \theta}{\partial n}+u \frac{\partial \theta}{\partial s}=-\frac{1}{\rho C_{\mathrm{p}}} \frac{\partial R_{\mathrm{n}}}{\partial n}-\frac{\partial\left(\overline{w^{\prime} \theta^{\prime}}\right)}{\partial n}
$$

Mass

$$
\frac{\partial u}{\partial s}+\frac{\partial w}{\partial n}=0
$$

The wind above the boundary layer is assumed to be geostrophic and exclusively in the $y$-direction, so that the first term on the righthand side of Equation (3) allows for the velocity gradient above the boundary layer. It is assumed that this is a linear profile so that $\left(\partial V_{\mathrm{g}} / \partial n\right) \approx$ $\left(V_{\mathrm{g}} / h\right)$. The second term on the righthand side of Equation (2) can be replaced by the pressure-gradient force of the free atmosphere and the effect of the thermal wind between the free atmosphere and the boundary layer, so that

$$
-\frac{1}{\rho} \frac{\partial p}{\partial s}=f V_{\mathrm{g}}-\frac{1}{\rho} \frac{\partial}{\partial s}\left(p-p_{\mathrm{a}}\right) .
$$

Neglecting vertical accelerations with respect to the pressure variation, the hydrostatic equation can be rewritten as follows:

$$
\frac{1}{\rho} \frac{\partial\left(p-p_{\mathrm{a}}\right)}{\partial n}=-g \frac{\Delta \theta}{\theta_{\mathrm{br}}} \sin \alpha .
$$

This can be integrated with respect to $n$ and substituted into Equation (2) using Equation (7).

\subsubsection{The profile factors}

The vertical profiles of $u, v,\left(\overline{w^{\prime} \theta^{\prime}}\right)$ and $\theta$ are given in Figure 2. The integration of Equations (2)-(6) assumes well-mixed flow with average mean layer-velocity components $U$ and $V$ and, following Ellison and Turner 


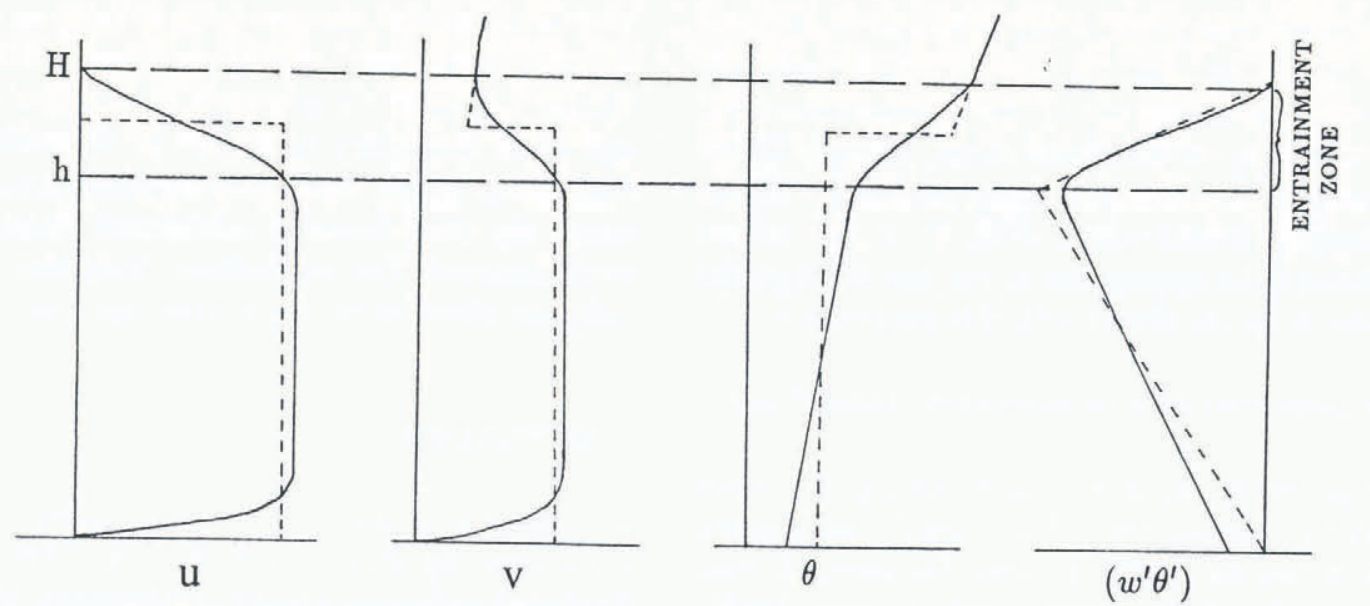

Fig. 2. Schematic of the vertical profiles of the wind velocity components $U$ and $V$, potential temperature and vertical heat flux of the boundary layer (solid lines) and profiles used in the model (dashed lines).

(1959) and Manins and Sawford (1979), profile factors are introduced to scale the integrals in order to account for deviations from well-mixed flow. These profile factors $\left(S_{1}, S_{2}\right.$ and $\left.S_{3}\right)$ are defined by the following equations:

$$
\begin{aligned}
S_{1} g h^{2} \frac{\Delta \theta}{\theta} & =2 \int_{0}^{H} g n \frac{\Delta \theta}{\theta} \mathrm{d} n \\
S_{2} g h \frac{\Delta \theta}{\theta} & =\int_{0}^{H} g \frac{\Delta \theta}{\theta} \mathrm{d} n \\
\int_{0}^{H} w \mathrm{~d} n & =W_{\mathrm{e}} H-S_{3} W_{\mathrm{e}} h
\end{aligned}
$$

where $h$ is the depth of the boundary layer, scaled using the profile factors in Equations (9)-(11), $H$ is the height assumed to be unaffected by katabatic flow and $W_{\mathrm{e}}$ is the entrainment velocity. If there was no entrainment, $h$ would be at the same height as $H$ (personal communication from J. P. Gosink, 1991), and there would be a discontinuity at the top of the boundary layer. For wellmixed katabatic flow, $S_{1}=S_{2}=S_{3}=1$. The profile factors account for the distribution of the density relative to the buoyancy profiles, and arise because integrating each according to average characteristics of the layer is not strictly equivalent to summing the integrals of each of the sub-layers within the boundary layer.

$S_{1}$ accounts for the fact that both $\Delta \theta$ and $\theta$ in the equation describing the pressure distribution associated with the thermal wind (Equation (9)) are functions of $n$. $S_{2}$ in the integration of the buoyancy Equation (10) allows for the deviations in the value of $\theta$ throughout the layer. However, variations in the ambient density are likely to be relatively small compared to the other terms, and on this basis the value of $S_{2}$ is generally close to unity. $S_{3}$ is associated with the vertical velocity within the boundary layer. Rather than defining a mean value for the layer, the value at $H$ is used in accordance with entrainment theory (Manins and Sawford, 1979). Entrainment of air from above the boundary layer into the katabatic flow will induce a vertical velocity, $W_{\mathrm{e}}$, in the ambient air which will ultimately result in a velocity parallel to the isotherms in a stably stratified environment (Manins and Sawford, 1979). For horizontal isotherms, this small horizontal velocity, $U_{\mathrm{H}}$, is related to $W_{\mathrm{e}}$ by the following equation

$$
U_{\mathrm{H}} \sin \alpha=W_{\mathrm{e}} \cos \alpha .
$$

This should be taken into account in the integration of the flow speed $U$, as follows:

$$
\int_{0}^{H} u \mathrm{~d} n=U h+U_{\mathrm{H}} H .
$$

Unless $H$ is much larger than $h, U_{H} \ll U$ so that the second term on the righthand side of Equation (13) can be neglected, except in the integration of the equation governing the conservation of heat (Equation (5)).

Using these profile factors, and using Equations (8)(11), Equations (2)-(5) are integrated in the $n$-direction to height $H$, and in the $y$-direction around the circumference of the ice sheet $y_{\mathrm{i}}$. Replacing $(\partial \theta / \partial n)$ and $(\partial \theta / \partial s)$ with $(\partial \theta / \partial z)$, according to Figure 1 , parameterizing surface stress according to $-\tau_{\mathrm{f}} / \rho=$ $C_{\mathrm{d}} U^{2}$ and neglecting second-order derivatives, gives the following set of equations describing the evolution of the mean layer-velocity components $(U$ and $V)$, the depth of the layer $(h)$ and the temperature deficit $(\Delta \theta)$ :

$$
\begin{aligned}
\frac{\mathrm{d} U}{\mathrm{~d} s} & =S_{2} g \frac{\Delta \theta}{\theta_{\mathrm{br}} U} \sin \alpha+\frac{f}{U}\left(V_{\mathrm{g}}-V\right) \\
& -S_{1} \frac{1}{U h y_{\mathrm{i}}} \frac{\mathrm{d}}{\mathrm{d} s}\left[g \frac{\Delta \theta}{\theta_{\mathrm{br}}} \frac{h^{2}}{2} y_{\mathrm{i}} \cos \alpha\right]+\frac{W_{\mathrm{e}}}{h}-\frac{C_{\mathrm{d}} U}{h} \\
\frac{\mathrm{d} V}{\mathrm{~d} s} & =f-\frac{W_{\mathrm{e}}}{U h}\left(V_{\mathrm{g}}-V\right)-\frac{C_{\mathrm{d}} V^{2}}{h U} \\
\frac{\mathrm{d} \Delta \theta}{\mathrm{d} s} & =\frac{R_{\mathrm{div}}}{\rho C_{\mathrm{p}} h U}-\frac{\mathrm{d} \theta}{\mathrm{d} z}\left(\sin \alpha-S_{3} E \cos \alpha\right)+\frac{\Delta \theta W_{\mathrm{e}}}{h U} \\
\frac{\mathrm{d} h}{\mathrm{~d} s} & =-\frac{W_{\mathrm{e}}}{U}-\frac{h}{U} \frac{\mathrm{d} U}{\mathrm{~d} s}-\frac{h}{y_{\mathrm{i}}} \frac{\mathrm{d} y}{\mathrm{~d} s}
\end{aligned}
$$

where $R_{\text {div }}$ is the net radiative divergence across the depth of the boundary layer and $f$ is the Coriolis parameter.

The model is valid for shooting flow which assumes a critical Richardson number (see e.g. Ball, 1956; Lalaurette and André, 1985), defined by Equation (18) to be less than unity:

$$
\mathrm{Ri}_{\mathrm{c}}=S_{1} \frac{g h \Delta \theta}{\theta_{\mathrm{br}} U^{2}} \cos \alpha
$$


This occurs where the slope is large enough so that the layer velocity exceeds the velocity of small-amplitude gravity waves ( $N$ in Equation (1)). Over East Antarctica, this occurs at the top of the glacial slope, around $700 \mathrm{~km}$ from the centre of the ice sheet (approximately $300 \mathrm{~km}$ from the margin). Initial values of $U, V, h$ and $\Delta \theta$ are therefore chosen to be appropriate to the top of the glacial slope in order to be consistent with this assumption.

\subsection{Model parameters and boundary conditions}

The profile factors $S_{1}, S_{2}$ and $S_{3}$ have been given values of $0.5,0.9$ and 1.0 , respectively. These are the same as the values used by Gosink (1989). Further discussion of these values can be found in Ellison and Turner (1959), Manins and Sawford (1979), Lalaurette and André (1985) and Hall (1992). The cooling rate $\left(R_{\text {div }} / \rho C_{\mathrm{p}}\right)$ is taken to be $0.03 \mathrm{~K} \mathrm{~m} \mathrm{~s}^{-1}$, equivalent to a heat loss from the boundary layer of around $30 \mathrm{Wm}^{-2}$, and is the same as the value used by Gosink (1989). This value compares well with the observed net longwave flux from the surface of the Antarctic ice sheet (Schwerdtfeger, 1984), which should be close to the net flux divergence, since the net radiative flux at the top of the boundary layer is small.

The drag coefficient in the $x$-direction, $C_{\mathrm{du}}$, is given a value of 0.0015 . This is consistent with previous studies, e.g. Inoue (1989), Gosink (1989). A larger value is used in the $y$-direction and $C_{\mathrm{dv}}$ is taken to be 0.04 . This is to take account of other processes which may retard the flow in this direction, which are not included explicitly in the model, namely:

Pressure variations. There is no pressure-gradient force in Equation (15). If the ice sheet was a perfect dome with a perfectly circular anticyclonic pressure field, this would hold true. Deviations from this ideal case arise due to cross-valley undulations and large mountain ranges, such as the Trans-Antarctic Mountains.

Gravity wave drag. This may be topographically induced and has been observed to retard the flow over Antarctica by up to $10 \mathrm{~m} \mathrm{~s}^{-1}$ (Mobbs and Rees, 1989), where ridges and valleys tend to have their axes orientated perpendicularly to the $v$ component of flow.

Sastrugi. At a much smaller scale, sastrugi orientated in the direction of prevailing flow, cause additional roughness of the surface perpendicular to their lineation; they may be of the order of $5 \mathrm{~m}$ in size, which could impose a significant drag force on the flow. In a study over Antarctica, Inoue (1989) found the roughness height to be greater perpendicular to the orientation of sastrugi.

If $C_{\mathrm{dv}}$ is too small, the Coriolis force begins to dominate the evolution of the $U$ component of flow, and the drainage flow becomes supercritical. The geostrophic wind is assumed to be exclusively in the $y$-direction. This is approximately true of the flow over Antarctica (e.g. Lettau and Schwerdtfeger, 1967; Schwerdtfeger and Mahrt, 1968; Schwerdtfeger, 1970), where it is generally observed to be between 2 and $5 \mathrm{~m} \mathrm{~s}^{-1}$, but these values may be exceeded over Greenland and past ice sheets. In the work presented in this paper a value of $3 \mathrm{~m} \mathrm{~s}^{-1}$ is used. Higher values of the geostrophic wind produce a deeper and faster boundary layer due to the additional downslope force (Hall, 1992). If the geostrophic wind is too small, the flow becomes subcritical where the slope is small because the down-slope buoyancy force is not sufficient alone to maintain drainage flow.

\section{ENTRAINMENT}

Entrainment is parameterized according to the formulation used by Ellison and Turner (1959), which was developed following a series of laboratory experiments. It has been used by several authors to describe the entrainment process into the boundary layer over ice (e.g. Manins and Sawford, 1979; Gosink, 1989). The equation for entrainment is given by

$$
-W_{\mathrm{e}}=E \mathrm{U}=\frac{A_{\mathrm{c}} \mathrm{U}}{S_{1} \mathrm{Ri}+A_{\mathrm{k}}}
$$

where $E$ is the entrainment coefficient and $A_{\mathrm{c}}$ and $A_{\mathrm{k}}$ are both constants, with values of 0.0004 and 0.02 , respectively, these are the same as those used by Gosink (1989), $S_{1}$ is the profile factor described earlier and $\mathrm{Ri}$ is the Richardson number for the layer given by

$$
\mathrm{Ri}=\frac{g h \Delta \theta}{\theta \mathrm{U}^{2}} \text { where } \mathrm{U}^{2}=U^{2}+V^{2} \text {. }
$$

\section{MODEL RESULTS}

Figure 3 shows the evolution of the model boundary layer over two different profiles. The solid line represents a surface profile of Terre Adélie, Antarctica (Drewry, 1983), and the dotted line is an idealized profile of the form described in Equation (21) with surface slope angle $\tan \alpha=\mathrm{d} H_{\mathrm{i}} / \mathrm{d} x$.

$$
H_{\mathrm{i}}=h_{\mathrm{d}}\left[1-\left(\frac{x}{S_{\mathrm{p}}}\right)^{\left(n_{\mathrm{g}}+1\right) / n_{\mathrm{g}}}\right]^{n_{\mathrm{g}} /\left(2 n_{\mathrm{g}}+1\right)} .
$$

The model was initialized at the top of the slope $(300 \mathrm{~km}$ from the margin) with a temperature deficit $(\Delta \theta)$ of $12 \mathrm{~K}$, consistent with observations (e.g. Parish and Waight, 1987). Initial values of $U, V$ and $h$, were chosen iteratively to eliminate any abrupt changes in $U, V, h$ or $\Delta \theta$ at the top of the slope. On this basis, for the Terre Adélie profile $U_{1}=10.4 \mathrm{~m} \mathrm{~s}^{-1}, V_{1}=3 \mathrm{~m} \mathrm{~s}^{-1}$ and $h_{1}=245 \mathrm{~m}$. For the idealized profile $U_{1}=12.0 \mathrm{~m} \mathrm{~s}^{-1}$, $V_{1}=3 \mathrm{~m} \mathrm{~s}^{-1}$ and $h_{1}=235 \mathrm{~m}$. For the Terre Adélie profile, the resultant wind speed increases from $10.8 \mathrm{~m} \mathrm{~s}^{-1}$ to around $16 \mathrm{~m} \mathrm{~s}^{-1}$ at the coast, the largest acceleration occurring in the region of rapidly increasing slopes in the coastal strip. There is a tendency for the wind to be orientated more nearly perpendicular to the contours as the coast is approached, so that at the margin the $U$ and $V$ components of the wind speed are 15.48 and $3.73 \mathrm{~m} \mathrm{~s}^{-1}$, respectively. The temperature deficit decreases from $12 \mathrm{~K}$ to around $4 \mathrm{~K}$. Both these features show a generally good agreement with the observations and 

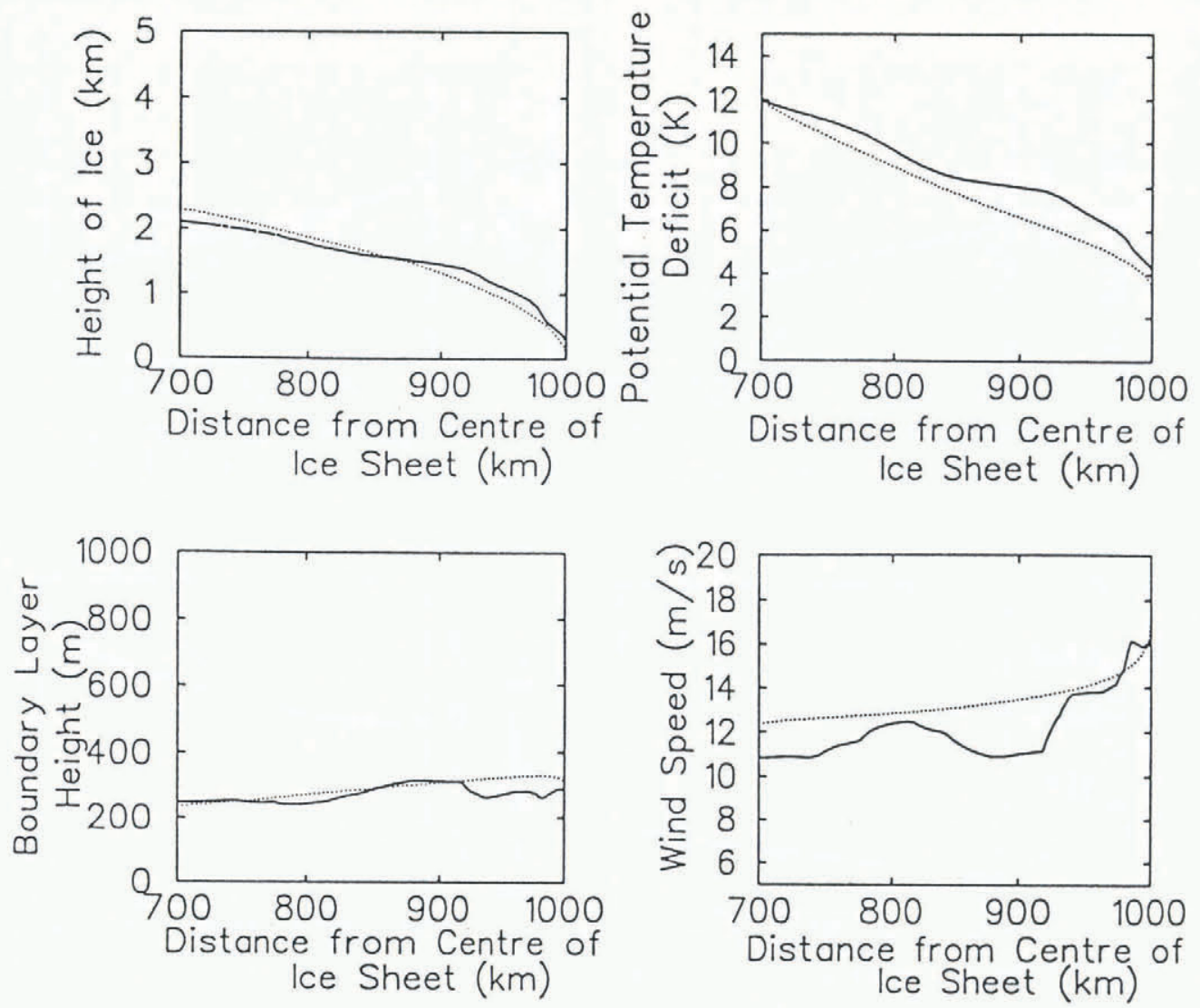

Fig. 3. The evolution of the boundary layer according to the model using a profile taken from Terre Adélie in Antarctica (solid line) and an idealized profile described in the text (dotted line).

numerical model results of Parish and Waight (1987). From the observations of Phillpot and Zillman (1970), the temperature deficit is between 10 and $15 \mathrm{~K}$ on the glacial slopes, decreasing to between 2 and $5 \mathrm{~K}$ at the coast and the wind-speed observations of Mather and Miller (1967) show an increase from around $10 \mathrm{~m} \mathrm{~s}^{-1}$, orientated at $45^{\circ}$ to the slope at Pionerskaya, to around $18 \mathrm{~m} \mathrm{~s}^{-1}$, orientated at between $5^{\circ}$ and $15^{\circ}$ at the coastal sites of Port Martin and Cape Denison. The layer depth of the slab model is slightly less than that which is observed, around $300 \mathrm{~m}$, rather than increasing from 300 to $400 \mathrm{~m}$.

The idealized profile shows a reasonable agreement with these results, although the absence of the detailed slope structure, especially in the upper regions of the slope, causes the wind speed to be too high, and the acceleration in the lowest $100 \mathrm{~km}$ is less. The broad features of boundary-layer development, namely an increasing wind speed becoming orientated closer to the line of the maximum slope, the slight increase in boundary-layer depth and decrease in temperature deficit are reproduced, giving confidence in the model results. Therefore, the use of idealized profiles in the following section seems reasonable.

\subsection{The effect of ice-sheet shape and size}

Model runs have been carried out using ice sheets of different size and shape to investigate the boundary-layer evolution as an ice sheet grows. The ice-sheet profile in these cases is always of the form

$$
\left(\frac{H_{\mathrm{i}}}{h_{\mathrm{d}}}\right)^{2}=\left(1-\frac{x}{s_{\mathrm{p}}}\right)
$$

where $H_{\mathrm{i}}$ is the height of the ice above mean sea level, $h_{\mathrm{d}}$ is the height of ice at the divide, $x$ is the horizontal distance from the ice divide and $s_{\mathrm{p}}$ is the span of the ice sheet. In the first group of experiments (Fig. 4), the ice sheet is allowed to maintain a similar shape, but successively smaller spans are used; for profile 1 , $h_{\mathrm{d}}=2.4 \mathrm{~km}$ and $s_{\mathrm{p}}=500 \mathrm{~km}$, for profile $2, h_{\mathrm{d}}=$ $1.75 \mathrm{~km}$ and $s_{\mathrm{p}}=360 \mathrm{~km}$, and for profile $3, h_{\mathrm{d}}=$ $1.25 \mathrm{~km}$ and $s_{\mathrm{p}}=215 \mathrm{~km}$. A second group of experiments, shown in Figure 5, was carried out where the maximum height of the ice was changed in each case, while the span $s_{\mathrm{p}}$ was kept constant at $500 \mathrm{~km}$; in profile $4, h_{\mathrm{d}}=1.75 \mathrm{~km}$, and in profile $5, h_{\mathrm{d}}=1.25 \mathrm{~km}$. At the top of the slope ( $100 \mathrm{~km}$ from the centre), the profiles are almost identical and the initial boundary-layer depth at the top of the slope, $100 \mathrm{~km}$ from the centre, is taken to be $110 \mathrm{~m}, \Delta \theta_{1}$ is given a value of $6 \mathrm{~K}$ and $V_{1}$ a value of $2 \mathrm{~m} \mathrm{~s}^{-1}$ in each case. Initial values of $U$ have been chosen to allow smooth boundary-layer development; for profiles 1 to 5 , these are $5.4,5.5,6.0,5.0$ and $4.6 \mathrm{~m} \mathrm{~s}^{-1}$, respectively. The results in Figure 4 show that, as the ice sheet shrinks, the temperature deficit, boundary-layer depth and wind speed all change more rapidly, but conditions at the margin of the ice sheet are little changed. The second group of experiments (Fig. 5) indicates that a flatter ice sheet causes the layer to slow down, there is less entrainment and the increase in the radiative time-scale relative to the advective time-scale tends to produce a colder boundary layer dominated by radiative rather than turbulent processes. The difference in the temperature deficit between the profiles exceeds $1 \mathrm{~K}$. 

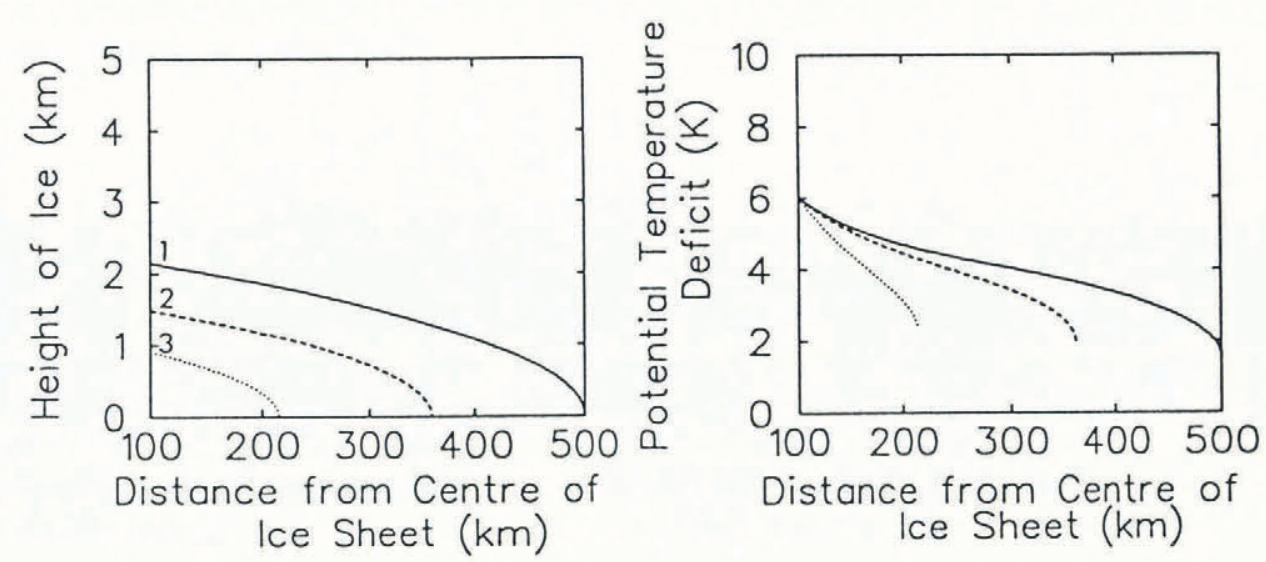

Distance from Centre of lce Sheet $(\mathrm{km})$
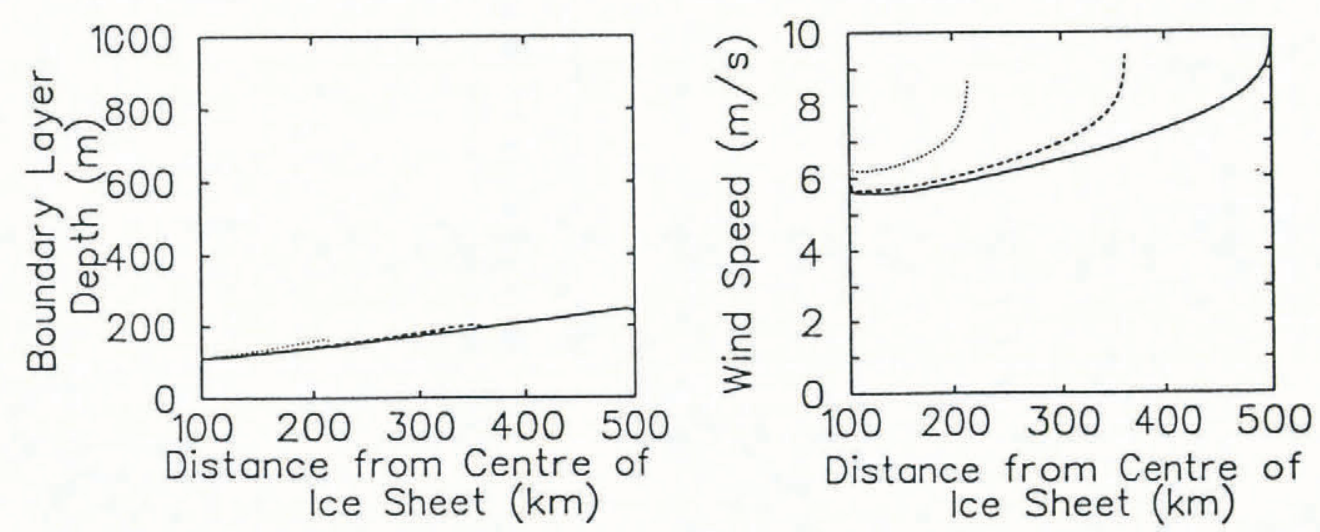

Fig. 4. The evolution of the boundary layer for three different idealized profiles with similar shape but different spans (see text for details).
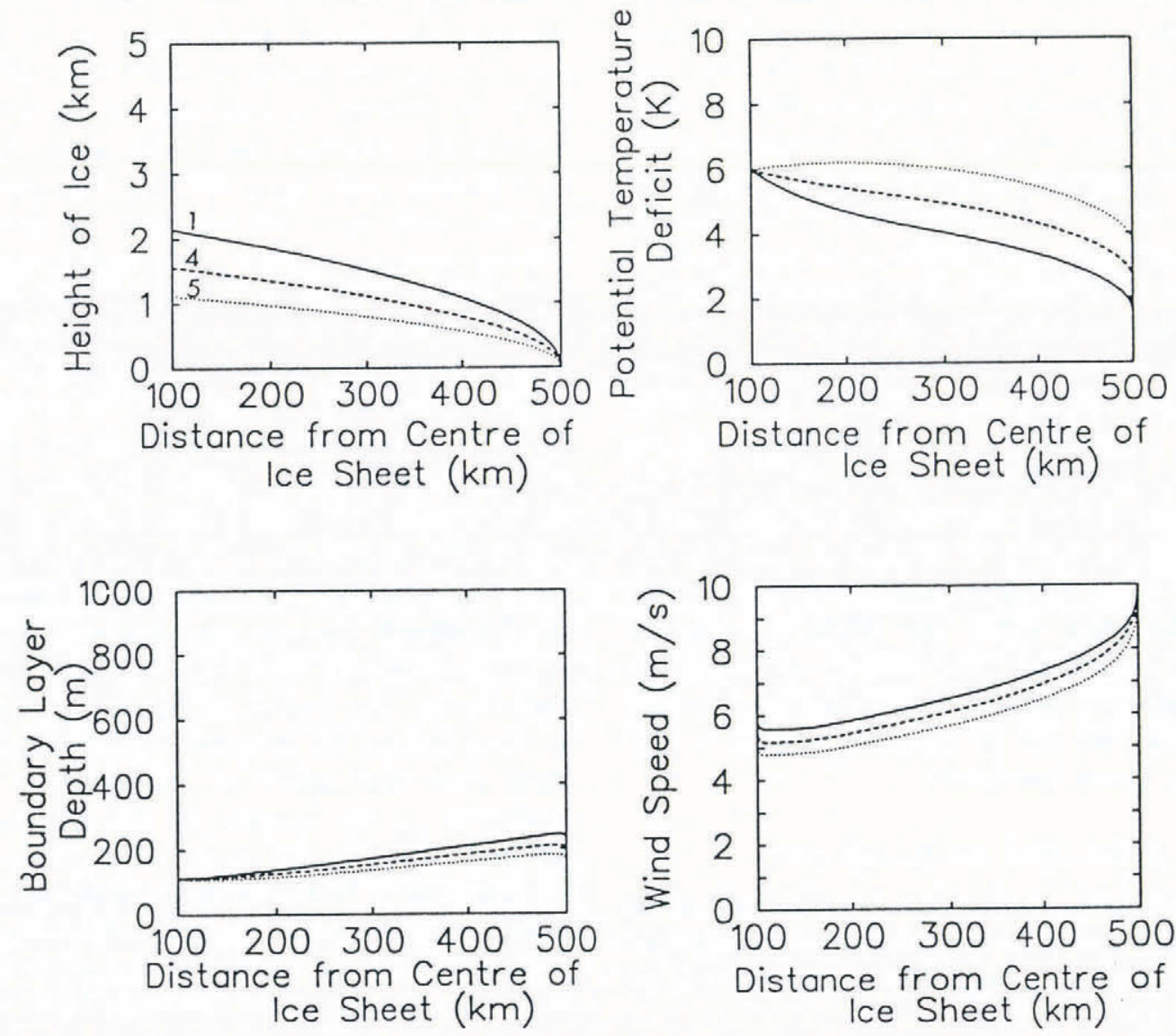

Fig. 5. The evolution of the boundary layer for three different idealized profiles, having the same span but with different slopes (see text for details). Profile 1 is the same as that in Figure 4. 
The ablation of ice on an ice sheet depends on the energy budget at the surface as well as the temperature; therefore any model which attempts to assess the potential ablation of ice should include an energy-balance model, but these results show that the evolution of the boundary layer is also important. Investigations by Braithwaite and Olesen (1990) suggest that the Greenland ice sheet is becoming steeper as it retreats. If this is the case, the results presented here suggest that entrainment of warm air into the boundary layer contributes significantly to the existing ablation.

\section{CONCLUSIONS}

The experiments presented in this paper show that the evolution of the boundary layer depends on an interplay between ice-sheet slope, entrainment and radiation budget. In particular over the flatter ice sheets, where flow is slower, entrainment is reduced and the radiation balance begins to dominate the heat budget of the boundary layer. In the case where the ice sheet is steeper, the flow is much faster and the additional entrainment introduces a large amount of heat to the surface layer, which would be significant for the ablation of ice. Thus, steeper profiles tend to produce warmer boundary layers. Boundary layers over ice sheets with the same shape but different spans appear to differ only in the horizontal distance over which the change takes place. Of more significance in this case is the temperature deficit, which is likely to be reduced on a smaller ice sheet where the opportunity for radiative cooling over the central plateau is less.

\section{DISCUSSION}

Experiments with ice-sheet models show the evolution of ice to be sensitive to ablation. Ablation is generally modelled using either energy-balance considerations or more simple degree-day models. This paper has shown that the detailed boundary-layer properties, especially entrainment, are also important, and that an evolving boundary layer over an evolving ice sheet is likely to produce feed-back effects, so that, as the ice profile becomes steeper, there is more ablation. Entrainment is greatest near the edge of the ice sheet, therefore the effect is likely to be more marked at low altitude, steepening the profile further.

The understanding of boundary-layer processes as it stands at present is inadequate. More observations are required, particularly those which enable an assessment of the entrainment of mass and heat into the boundary layer. The role of the geostrophic wind as a significant driving force to the drainage flow must also be considered. Work by Shinn and Barron (1989) and Kutzbach and Wright (1985) has demonstrated the changing strength of the glacial anticyclone and the mean meridional flow. Experiments with this model confirm the fact that the strength of the geostrophic wind is important for the maintainance of drainage flow, particularly where the slope is small, as has been found in similar studies over Antarctica (e.g. Lettau, 1966; Parish and Waight, 1987).
A detailed investigation of the interaction between the glacial anticyclone and the upper mean meridional flow, however, is beyond the scope of a single-layer model such as the one presented here, but should be a consideration of future work. This work has highlighted the need to take account of the interplay between ice-sheet shape and boundary-layer development, particularly entrainment, in estimating ablation of ice. Modelling projects in the future therefore should incorporate these boundary-layer processes. In this respect, the model is of use to both glaciologists and climatologists. It would be easily combined with a snow-melt model by incorporating an energy balance at the surface, and its simplicity means it could provide a parameterization of these important processes in GCMs which cannot explicitly reproduce these processes as they occur on a scale smaller than that of a typical model grid.

\section{ACKNOWLEDGEMENTS}

This work was partly supported by a studentship from the U.K. Natural Environment Research Council. The authors are grateful to the referees for helpful suggestions.

\section{REFERENGES}

Ball, F. K. 1956. The theory of strong katabatic winds. Aust. F. Phys., 9, 373-386.

Braithwaite, R.J. and O.B. Olesen. 1990. Increased ablation at the margin of the Greenland ice sheet under a greenhouse-effect climate. Ann. Glaciol., 14, 20-22.

Drewry, D.J., ed. 1983. Antarctica: glaciological and geophysical folio. Cambridge, University of Cambridge. Scott Polar Research Institute.

Ellison, T.H. and J.S. Turner. 1959. Turbulent entrainment in stratified flows. 7. Fluid Mech., 6, 423- 448.

Gosink, J. P. 1982. Measurement of katabatic winds between Dome C and Dumont d'Urville. Pure Appl. Geophys., 120, 503-526.

Gosink, J.P. 1989. The extension of a density current model of katabatic winds to include the effects of blowing snow and sublimation. Boundary-Layer Meteorol., 49(4), 367-394.

Hall, A.J. 1992. The interaction between climate and ice sheets: with special reference to the boundary layer of the ablation zone. (Ph.D. thesis, University of Edinburgh.)

Hyde, W. T. and W. R. Peltier. 1985. Sensitivity experiments with a model of the ice age cycle: the response to harmonic forcing. F. Atmos. Sci., 42(20), 2170-2188.

Inoue, J.N. 1989. Surface drag over the snow surface of the Antarctic Plateau. 1. Factors controlling surface drag over the katabatic wind region. J. Geophys. Res., 94(D2), 2207-2217.

Kodama, Y., G. Wendler and N. Ishikawa. 1989. The diurnal variation of the boundary layer in summer in Adelie Land, East Antarctica. F. Appl. Meteorol., 28(1), 16-24.

Kutzbach, J.E. and P.J. Guetter. 1986. The influence of changing orbital parameters and surface boundary conditions on climate

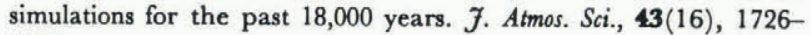
1759

Kutzbach, J.E. and H. E. Wright. 1985. Simulation of the climate of 18,000 years BP: results for the North American/North Atlantic/ European sector and comparison with the geologic record of North America. Quat. Sci. Rev., 4, 147-187.

Lalaurette, F. and J. C. André. 1985. On the integral modelling of katabatic flows. Boundary-Layer Meteorol., 33, 133-149.

Lettau, H. H. 1966. A case study of katabatic flow on the South Polar Plateau. Antarct. Res. Ser., 9, 1-11.

Lettau, H.H. and W. Schwerdtfeger. 1967. Dynamics of the surfacewind regime over the interior of Antarctica. Antarct. F. U.S., 2(5), 155-158. 
Manabe, S. and A.J. Broccolli. 1985. The influence of continental ice sheets on the climate of an ice age. F. Geophys. Res., 90(D1), 21672190.

Manins, P. C. and B. L. Sawford. 1979. A model of katabatic winds. F. Atmos. Sci., 36, 619-630.

Mather, K.B. and G.S. Miller. 1967. Notes on the topographical factors affecting the surface in Antarctica, with special reference to katabatic winds; and bibliography. Fairbanks, AK, University of Alaska. (Technical Report UAG-R-189.)

Mitchell, J.F.B., N.S. Grahame and K.J. Needham. 1988. Climate simulations for 9000 years Before Present: seasonal variations and effect of the Laurentide ice sheet. F. Geophys. Res., 93(D7), 8283-8303.

Mobbs, S.D. and J.M. Rees. 1989. Studies of atmospheric internal gravity waves at Halley Station, Antarctica, using radiosondes. Antarct. Sci., 1(1), 65-75.

Oerlemans, J. 1981. Modeling of Pleistocene European ice sheets: some experiments with simple mass-balance parameterizations. Quat. Res., 15(1), 77-85.

Parish, T. R. and K. T. Waight. 1987. The forcing of Antarctic katabatic winds. Mon. Weather Rev., 115, 2214-2226.
Phillpot, H.R. and J.W. Zillman. 1970. The surface temperature inversion over the Antarctic continent. F. Geophys. Res., 75(21), 41614169.

Schwerdtfeger, W. 1970. The climate of the Antarctic. In Orvig, S., ed. Climates of the polar regions. Amsterdam, Elsevier, 253-335. (World Survey of Climatology, Vol. 14.)

Schwerdtfeger, W. 1984. Weather and climate of the Antarctic. Amsterdam, Elsevier.

Schwerdtfeger, W. and L.J. Mahrt. 1968. The relation between the Antarctic temperature inversion in the surface layer and its wind regime. International Association of Scientific Hydrology Publication 86 (Symposium at Hanover 1968-Glaciological Exploration (ISAGE)), 308-315.

Shinn, R.A. and E.J. Barron. 1989. Climate sensitivity to continental ice sheet size and configuration. F. Am. Meteorol. Soc., 2(12), 15171537.

The accuracy of references in the text and in this list is the responsibility of the authors, to whom queries should be addressed.

MS received 18 June 1992 and in revised form 15 December 1992 